information they require, as students seeking academic degrees, can be placed in their hands effectively and efficiently.

There is one final aspect of our student supervisor program that has been of immeasurable benefit to our library in terms of service. The tasks performed by the student supervisors are so varied that these individuals are capable of moving easily from their positions as student workers to become regular staff employees within their departments. Approximately thirty percent of the regular, full-time staff currently employed by the Meriam Library started their library careers as student assistants and were involved in our student supervisor program. These individuals have, in many cases, been able to step from their student work into a staff job and almost immediately function at full capacity. Thus, the need for an extended training period has been eliminated for these employees, because they are knowledgeable about the department's policies and procedures on their very first day. This has permitted the periodic transitions in regular staffing, which occur because of transfers or retirement, to be smooth and relatively immune to temporary service slow-downs that typically occur as a new employee becomes familiar with the basics of a unit's operation.

In all, we have found that our student supervisor program has helped our library to provide a level of public and technical service that otherwise would probably have been unattainable. In addition, we have tapped a valuable, internal library resource for guidance towards improvements in our future service, and have given a number of bright, energetic, and enthusiastic young adults a chance to lay foundations for the leadership skills they will need throughout their careers. We believe it to be a good program that has served well all those involved with it, staff and students, and one that we look forward to continuing and expanding upon well into the next century.

\title{
Humor and creativity: Questions and answers
}

\author{
By Norman D. Stevens
}

Director

The Molesworth Institute

As librarians, answering questions-correctly or incorrectly-is our stock-in-trade; it is not surprising, therefore, to find that various aspects of the question and answer game lend themselves to creative approaches that generate humor. In some cases it is the questions that users ask at the information or reference desk that generate, usually unintentionally, the humor. In other cases special humor issues of library newsletters that contain mock advice to the library lorn are a special delight. In still other cases academic libraries have created imaginative forums in which to answer written comments, complaints, questions, or suggestions. Each brings its own unique view of the world of library humor.

\section{At the reference desk}

Nancy S. Osborne, of the SUNY College at Oswego Library, observes that, "students asking pre-exam questions fall in a number of categories: the desperate, the confident, the confused, the organized. The questions fall into categories too: thoughtful, cognitive; hasty, rapid; penetrating and searching; inane and perhaps irrelevant. ... [In responding] I maintain that the existence and willing utilization of an active, healthy, and operative sense of humor, can make all the difference."

Perhaps that is what Lynne S. Epstein, then of the University of Kansas Medical Center Library, had in mind when she answered the phone one day-in the midst of a discussion with her supervisor about eating-by saying, "Reference. This is Lynne. May I feed you?" The patron responded, "You certainly may. What are you serving?" Lynne's supervisor provided the final note of indignity by point out that, given Lynne's history of cooking failures, she might better have said, "Reference. Will you feed me?"

Equally baffling must have been the greeting given by an assistant at the Winnipeg Public Library, where Randy Reichardt worked, who answered the phone one day not with the usual, "Good afternoon. Information and Reference," but with the unusual, and perhaps more accurate, "Good afternoon. Reformation and Inference."

A startling miscue, although not in the context of a true information exchange with a patron, was generated by a colleague (to remain nameless) who, when leaving for the reference stacks with a 
patron one day, called out loudly to the student assistant at the desk, "I'm going to 'P."' Responding to his look of amazement, she hastily added, "the literature section is what I meant."

Such encounters are undoubtedly more frequent than we would admit but because they take the form of fleeting exchanges, which we may think reflect poorly on our professional skills, they remain largely unreported. We should instead, I would suggest, treat them as a part of the joy of working with library users and cherish and share them.

\section{Advice columns}

Given the widespread distribution of various kinds of advice columns in contemporary American newspapers, it is not surprising to find that the mock library newsletters that satirize the foibles of our best academic libraries often contain advice columns of one kind or another. Such columns are not, unfortunately, a regular feature of any "real" library newsletter of which I am aware. That's too bad, for the format certainly allows for an honest and open exchange of information and opinion.

The Library Muse, from the University of Missouri Library, and Torn Sheet, from the University of Wyoming Library, have regularly contained such columns. "The Muse Advisor," which is accompanied by a picture of a properly sage bearded gentleman, is an attempt to offer recourse to the dissatisfied, an ear to the unheard, and answers to the curious. "Ask Miss Behavior . ...", which is accompanied by a silhouette of an elegant lady, offers no explanation of its purpose. Both offer many words of wit and sometimes even wisdom.

"The Muse Advisor," for example, often deals with the little problems that all library staff face such as clocks, elevators, restrooms, temperature, and other malfunctioning systems that plague most academic libraries but that no self-respecting library administrator will deign to deal with. The questions highlight the problems even if the answers fail to provide adequate responses perhaps, in their own fashion, paralleling the inadequate responses that are typically provided to such questions when they are asked in a serious way. "Shivering in Shelving" asks, "It seems that no matter what the season, my hands and feet are always cold. Sometimes they even take on a bluish cast. What can I do?" "The Muse Advisor" sagely responds, "I'm hardly a physician, but it sounds a though you should take your problem to someone in circulation."

“Ask Miss Behavior ..." takes a similar approach but tends to concentrate on the etiquette of library behavior and the image of the librarian. "Gentle Reader" (for so all of her inquirers are identified) asks, "What should one do when one is browsing in the stacks and suddenly meets a gentleman clad only in a ski mask?" "Miss Behavior" gently responds, "Present him with a preprinted card listing local agencies that supply clothing to the needy. Since one does not wish to encourage 'hanging out' in the stacks, it would be prudent to scrutinize the gentleman carefully for identifying features (such as tattoos) in case he should return."

Another "Gentle Reader" asks, "I've been hearing about the 'Magic Marker Makeup' trend, but since I've never used much makeup of any kind, I really don't know what to make of this. ... I need advice on this before my big debut [as a consultant] next week!" "Miss Behavior" responds, in part, "Wise woman! The right magic marker can give your presentation that je ne sais quoi we all desire.

\section{Feeling funny?}

After only nine of these columns I have at last provoked enough of you so that I am now the regular recipient of a wide assortment of academic, and other, library humor. I note withas Rose Simon of Salem College wrote to me in another context-" "glee and approbation (glee is pitched up two octaves higher than approbation: it's like working with tweeters and woofers)" that I have even encouraged some of you to produce such stuff both in your own libraries and for $C \triangleleft R L$ News. One of my original goals has thus been accomplished. Keep it up!

My attack on that most sacred of library institutions - the committee-evoked two intriguing responses. J. James Mancuso, of the Capitol District Library Council in Schenectady, New York, defended committees by pointing out that, "If it were not for committees, heaven help us, I would actually have to do my work." Jean P. Black, librarian emerita of Portland State University, quoted a commercial card that announced that, "Our meetings are held to discuss many problems which would never arise if we held fewer meetings."

All of those contributions have persuaded me not to abandon my labors in this vineyard just yet. So, once again, I renew my plea for either contributions or suggestions. Even if you don't have specific gems of academic library humor-intentional or unintentional - to send my way, let me know what sacred aspects of academic librarianship you think deserve to be subject to my scrutiny. The address is still 143 Hanks Hill Road, Storrs, CT 06268. Material can also be faxed to me at (203) 486-3593. For those of you with electronic access I can be reached via Alanet (ALA1625) or Bitnet (HBLADM3@UCONNVMS). 
I hope you know what season you are (you have had your colors done haven't you?).... Marks-a-lot and El Marko give even coverage and last forever, but Sheaffer is marketing a slightly more upscale line with sunscreen and skin conditioner which I am sure you will be able to afford in your new line of business!"

\section{Formal features}

A number of academic libraries-probably more than we realize-have adopted creative formal systems for responding to questions from users that, in a substantial number of cases, make frequent and good use of humor in dealing with the inquiries. Such systems are often, as Sherman Hayes of the Bentley College Library points out, devices that can deflect the complaint level even though you may already know what the questions will be. He suggests - and others practice-that the best technique is to answer the question in the same tone as it was asked. Names are frequently an important attribute of such systems. The University of Connecticut Library once had, in pre-feminist days, a Bitch Box, while the University of North Dakota Library had a Bitch and Bonus Board. Sometimes the whole thing takes on a personality of its own. At Bentley College it is Sol while at the Law Library at the University of California at Berkeley it is Zeb.

The questions most commonly asked are, like those dealt with in the advice to the library lorn columns described above, about such mundane but important matters as change, cleaning, clocks, copying machines, noise, pencil sharpeners, restrooms, telephones, and the like. Emily, at the University of Baltimore Law Library, suggests, for example, that "Cleanliness is next to Impossible" in responding to the question, "Why aren't the study carrels cleaned out and disinfected weekly? Some of them are truly disgusting." She ventures that, "[The Housekeeping Department] will tell me cheerfully and cooperatively that they will ask staff to check the carrels more often. Then they'll tell me that they don't have enough money to keep the whole place clean (which is probably true), and they'll suggest that if students would stop bringing ten-course meals and pizza and all matter of gooey stuff into the library, that it would be easier to keep the carrels clean. I'll ask the library's official Carrel Light-Bulb-Checker if she would also check the Goo Factor of the carrels as she goes by. A Goo Factor of 5 or more will warrant a report to Housekeeping."

One of the most creative of these systems is "The Question Board" in the Undergraduate Library at the University of Illinois at Urbana-Champaign that is, primarily, a serious short-answer reference system. It has been more than adequately de- scribed by Donna Pitman in "The Question Board" in the June 1987 issue of none other than $C \mho R L$ News (pp. 327-30). As an institution that is now widely respected on campus and frequently publicized locally, this system seems destined, fortunately, to endure in its present format for some time to come.

Even during times of financial difficulties, "The Question Board" seems to be an essential service that manages to avoid the lurking budgetary axe. The questions remain posted on the original scraps of paper on which they are typically submitted. They are transferred to a notebook for recordkeeping purposes, but when neatly typed versions of the questions were posted, complaints about censor-

\section{Accreditation experts directory}

ACRL has just begun to prepare a directory of individuals with expertise in specific topics of interest to academic librarians and administrators. The primary purpose of the directory is to facilitate the advisory work of ACRL by providing a current source of information for librarians or administrators who may be looking for speakers, consultants, authors, or data. One area selected for priority is that of accreditation, specifically institutional and specialized.

Accordingly the ACRL Accreditation Experts Directory Advisory Board ( $a d$ hoc) is now soliciting applications from individuals who enjoy expertise in the area of accreditation. Basic criteria are as follows:

1. An ALA-accredited degree in library or information science.

2. Knowledge of academic librarianship, its role in higher education, and the accreditation process.

3. Interpersonal, communication, and organizational skills.

4. Service as a member on three or more accreditation teams for a regional accrediting association (Middle States, Southern, Western, etc.) or professional association (National Council for Accreditation of Teacher Education, Accreditation Board of Engineering and Technology, etc.).

Anyone who meets these criteria and who is willing to be listed in the Accreditation Experts Directory should request an application from: David B. Walch, Dean of Library Services, Kennedy Library, California Polytechnic State University, San Luis Obispo, CA 93407; (805) 756-2345. If you have any questions about the directory, contact any member of the Advisory Board, which includes Mignon Adams, Keith Cottam, Barbara Williams-Jenkins, and David Walch. 
ship and control quickly brought an end to that practice. An electronic version is under consideration but its lack of the personal touch is a major concern. It seems unlikely, in any case, that an electronic version could ever have the attraction, charm, and visibility of the original. Ms. Pittman, like Ms. Osborne, suggests that through this approach to answering reference questions "Staff members ... can add a touch of geniality or humor in their manner of answering."

\section{Using a DBMS to maintain a reserve reading collection}

\section{By Gregory A. Crawford}

\author{
Reference and Public Services Librarian \\ Moravian College
}

One of the most heavily used collections in Reeves Library at Moravian College is the reserve reading collection. This collection contains photocopies of articles, books, videotapes, slide/tape presentations, computer software, and cassette tapes for language instruction. This article will discuss the results of using a microcomputer-based database management system to maintain a reserve reading collection. The system discussed was used for a period of two years until being rep]aced by the Dynix reserve book room software module.

Since the collection continually grew and was constantly in a state of change, it quickly outgrew the manual system by which it was maintained. The first step in automating the collection was taken by the librarian in charge of circulation. She studied how other local colleges and universities handled their reserve collections and ultimately modeled her system on that in use at Lehigh University.

In the collection, each item was given a unique number. Books used in college courses received a plain number (e.g., 96), books used in seminary courses were indicated by an " $\mathrm{S}$ " preceding the number (e.g., S-96), and photocopied materials received a number preceded by "P" (e.g., P-96). All items were also color-coded to indicate their circulation status: orange bands indicated a two-hour circulation period, while yellow bands showed that the item may leave the library for an instructorspecified length of time which varied from overnight to seven days.

Students were hired to develop and maintain a database for this collection, thus becoming the first step toward automation in the library. Various students over a span of several years used a Unix editor to create records for the items on reserve. These were ASCII text files which used hard tabs to indicate individual fields. The students a]so wrote and continually enhanced a Pascal program that sorted the records into various lists that could then be printed on demand. Three major printouts were run, each preceded by the appropriate sort algorithm: MASTRES, a complete listing of all items in the reserve collection; a list of items that were on reserve for classes taught in the current semester, called FALLRES, SPRGRES, and SUMRES to distinguish the semester; and NUMRES, a shelflist consisting of all items currently on reserve by their assigned numbers.

The system worked well, although the students who controlled the system varied considerably in their attention to details and depth of understanding of the reserves collection. Thus, the staff spent considerable time in comparing the printouts to the reserves worksheets and in proofreading them to clean up errors and inconsistencies.

Then one day the computer center announced to the library that the minicomputer on which the reserves system resided was going to be disconnected. This necessitated that we find another method to control the collection, preferably one that did not revert to a card-based system. Since the Reference and Public Services Department had recently been given a computer for use in word processing and database searching, a microcomputer-based system seemed logical. A simple, userfriendly database management program was sought out. Since the library had no funds with which to purchase one of the more expensive database management software packages, shareware was investigated and we decided to try PC-File III, produced by ButtonWare, Inc. After examining the software and designing a few trial databases, we purchased a registered copy of the software and went to the next phase of the project, i.e., transferring our records off the minicomputer to a floppy 